\title{
Interaction of two public health problems in Turkish schoolchildren: nutritional deficiencies and goitre
}

\author{
Betul Ersoy ${ }^{1, *} \dagger$, Hafize Sunalcan Günes ${ }^{2}$, Turkan Gunay ${ }^{3}, \mathrm{Ozge} \mathrm{Yilmaz}^{2}$, Erhun Kasirga ${ }^{4}$ \\ and Ayten Egemen ${ }^{5}$ \\ ${ }^{1}$ Celal Bayar University, Medical Faculty, Department of Pediatrics, Division of Pediatric Endocrinology, Manisa, \\ Turkey: ${ }^{2}$ Celal Bayar University, Medical Faculty, Department of Pediatrics, Manisa, Turkey: ${ }^{3}$ Dokuz Eylül University, \\ Medical Faculty, Department of Public Health, Izmir, Turkey: ${ }^{4}$ Celal Bayar University, Medical Faculty, Department of \\ Pediatrics, Division of Pediatric Gastroenterology, Manisa, Turkey: ${ }^{5}$ Ege University, Medical Faculty, Department of \\ Pediatrics, Division of Social Pediatrics, Izmir, Turkey
}

Submitted 27 April 2005: Accepted 2 February 2006

\begin{abstract}
Objective: The aim of the present study was to determine the interaction of and association between frequency of goitre detected by palpation, nutritional status evaluated by anthropometric indices and socio-economic status in school-aged children.

Subjects: One thousand and eighteen prepubertal and pubertal children (aged 6-14 years) attending primary schools in an urban area were included in this study.

Design and setting: All subjects were evaluated for the presence of goitre and nutritional status. Thyroid size was assessed using the World Health Organization's (WHO) palpation system (1960). Severity of protein-energy malnutrition (PEM) was based on WHO criteria. Children were grouped into four categories of socioeconomic status.

Results: Eight per cent of children were detected to have goitre by palpation. Body mass index and weight-for-height were significantly lower in children who had palpable goitre than in children who did not have goitre $(P<0.05)$. Frequencies of having palpable goitre and being stunted and underweight were especially higher in children with very low socio-economic status ( $P=0.016,0.01$ and 0.01 , respectively). Frequency of being stunted, underweight and wasted in children with palpable goitre did not change significantly according to socio-economic status $(P>0.05)$. In logistic regression analyses, the most important factor in detection of palpable goitre was socio-economic status $(B=0.517, P=0.004)$. Fathers' education and occupation were found to be most significant ( $P=0.031$ and 0.020 , respectively).

Conclusion: Children detected to have palpable goitre were thinner. However, nutritional disorders were not more frequent among children with palpable goitre compared with children without goitre. Goitre and nutritional deficiencies were more common in children with lower socio-economic status but the frequency of nutritional disorders in children with palpable goitre did not change according to socio-economic status.
\end{abstract}

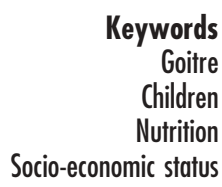

Goitre

Children

Nutrition

Socio-economic status
Goitre is a common clinical disorder during childhood and adolescence $^{1}$. The World Health Organization (WHO) established the criteria for determining goitre prevalence in $1960^{2}$, and revised and simplified these in 1994. Goitre was defined as any enlarged thyroid gland that is palpable and/or visible ${ }^{3}$. Palpation used to be the only method available for defining thyroid volume, but now ultrasonography is considered the most reliable method for the estimation of thyroid volume ${ }^{4}$. Goitre prevalence in

†Correspondence address: 108/35 Sokak no. 51/36, 35350 EsendereIzmir, Turkey. school-aged children is one of the main indicators of iodine deficiency in a population ${ }^{5}$. In areas of mild iodine deficiency, ultrasound is preferable to physical examination $^{6}$; however, because portable ultrasound equipment is not always readily available, especially in developing countries, palpation may be the only method for goitre detection.

Protein-energy malnutrition (PEM) is characterised not only by energy deficit due to reduced intake of all macronutrients, but also by deficits in many micronutrients ${ }^{7}$. If an increased goitre rate in childhood indicates iodine deficiency disorders (IDD), which is a 
micronutrient malnutrition ${ }^{5}$, it should be associated with generalised PEM. Additionally, similar to PEM, goitre prevalence is higher among children of low socioeconomic status ${ }^{8,9}$. Child malnutrition is an important indicator for monitoring progress 9 . In addition, normalisation of the goitre rate probably indicates the disappearance of IDD as a public health problem ${ }^{5}$. In the present study we evaluated growth parameters, socioeconomic status and palpable goitre rate of prepubertal and pubertal children attending primary schools in an urban area of Turkey. Therefore, we planned to determine the relative contribution of nutrition, assessed by anthropometric indices, and socio-economic status on the rate of goitre detection by clinical evaluation in schoolchildren.

\section{Study design and methods}

\section{Setting, sample selection and participants}

This study was undertaken among schoolchildren from the province of Manisa, situated in the west of Turkey. Manisa is located in an area of mountains although it is close to the sea (approximately $50 \mathrm{~km}$ ). Sampling was carried out in different stages to guarantee representativeness of the whole geographic area. The study was carried out in state primary schools. Schools were chosen from high and moderate socio-economic regions, slum and village areas. One primary school from each of the four different socio-economic levels was chosen at random for participation in the study. Eight classes were selected from each school. Children present in all 32 classes were included in the study group, which consisted of 1018 children. Students in state schools who come from various socio-economic backgrounds reflect Manisa's population better than the students in private schools. Permission was obtained from the Ministry of Education before commencing the study.

\section{Data collection}

First we identified sociodemographic features of the students. A questionnaire was administered to the children. Education and occupation of the parents were asked of each child and the answers were confirmed by the school directors. Clinical examination for goitre was performed by an expert endocrinologist using the traditional recommended method of palpation. Grading of goitre was done according to the criteria recommended by Perez et al. (0, thyroid not palpable; IA, thyroid palpable and larger than the distal phalanx of the subject's thumb; IB, goitre palpable and visible only with full neck extension; II, visible goitre with the neck in normal position $)^{2}$. Weight was measured to the nearest $0.5 \mathrm{~kg}$ using a balance beam scale and height was measured to the nearest $0.1 \mathrm{~cm}$ with a manual height board. Body mass index (BMI; $\mathrm{kg} \mathrm{m}^{-2}$ ) was used as an index of relative weight. Weight-for-height $(\mathrm{W} / \mathrm{H})$ was calculated. Height and weight standard deviation scores ( $Z$-scores) were calculated according to Turkish national standards, BMI $Z$-scores were calculated according to international standards. W/H $Z$-score was not calculated because the standards are given for up to 5 years of age.

The nutritional status of children was evaluated according to height and weight $Z$-scores. $Z$-score deficits (below minus two standard deviations, $<-2 \mathrm{SD}$ ) indicate the presence of two indicators of PEM: stunting and underweight. A low height-for-age Z-score (HAZ) $(<-2 \mathrm{SD})$ indicates stunting (stunted growth) and reflects failure to reach linear growth potential as a result of suboptimal health and/or nutritional conditions. A low weight-for-age $Z$-score (WAZ) $(<-2 \mathrm{SD})$ is considered to indicate underweight in the absence of significant wasting $^{10-12}$. In addition, BMI values less than $15 \mathrm{~kg} \mathrm{~m}^{-2}$ indicate total body fat content below $5 \%$ of body weight. That BMI is an important index of being thin was interpreted in children over 10 years of age ${ }^{13}$.

Categorisation of socio-economic status according to the Hollingshead index was based on the occupation and education of parents ${ }^{14}$. Socio-economic level was classified according to five educational categories and five occupational categories. A score of 0 was given to the lowest level of education and occupation and a score of 4 was given to the highest. Hollingshead scoring was modified according to national Turkish standards. Four socio-economic classes were identified ranging from lowest to highest on the basis of the sum of scores.

\section{Statistical analysis}

Data are presented as percentages, percentiles, means and $Z$-scores. Hypothesis contrast of continuous variables was made by the $t$-test for two comparisons. For qualitative variables, association was measured by the chi-square test. The Kruskal-Wallis test, Mann-Whitney $U$-test, one-way analysis of variance and Bonferroni analysis were used for comparisons between different socio-economic groups. Logistic regression was used to evaluate the association between anthropometric indices, socio-economic status and goitre detected by palpation.

\section{Results}

Mean age of the children was $11.19 \pm 1.30$ years (range $5.8-16.8$ years). Fifty-one per cent (519) of the children were male, $49 \%$ female. According to education and occupational level of their parents, students were included in very low (21.7\%), low (22.8\%), middle (21.6\%) or high (33.9\%) socio-economic status categories.

Frequency of goitre detected by palpation was $8.0 \%$ (81). Grading revealed that $67.9 \%$ (55) of these were grade IA, 29.6\% (24) were IB and only $2.5 \%$ (2) were grade II. We detected palpable goitre in $8.6 \%$ of girls, $7.3 \%$ of boys. Goitre was more common in girls but not significantly so $(P=0.488)$. 
HAZ and WAZ of children who had goitre were not significantly different from those of children who did not have goitre $(P>0.05)$. However, BMI $Z$-score and $\mathrm{W} / \mathrm{H}$ were significantly lower in children who had goitre by palpation than in children without goitre $(P<0.05)$ (Table 1). Anthropometric evaluation of the children revealed that $7.5 \%$ were stunted, $4.1 \%$ were underweight. Rate of goitre detection by palpation was higher in patients who were stunted and underweight, but the difference was not statistically significant $(P>0.05)$ (Table 2$)$.

The rate of detection of palpable goitre was significantly higher in children with low socio-economic status $(P<0.05)$ (Fig. 1) $\left(\chi \chi^{2}\right.$ for trend $=5.714, P=0.016$, odds ratio $(\mathrm{OR})=1.78)$. Evaluation of all children revealed that the frequency of stunting was significantly higher in children with low and very low socio-economic status $(P=0.0001)$. Similarly, the frequency of underweight was significantly higher in these children $(P=0.0004$, $\mathrm{OR}=3.1$ ). Underweight (BMI $<15 \mathrm{~kg} \mathrm{~m}^{-2}$ ) was significantly more frequent in children with low socio-economic status than in children with middle and high socioeconomic status ( $P=0.007$ ) (Fig. 2).

Among children with palpable goitre, HAZ and BMI $Z$ scores did not change according to socio-economic status but WAZ values were significantly higher in children with high socio-economic status $(P=0.008$ and 0.001 , respectively). All anthropometric indices in children without palpable goitre differed significantly between those with high and very low socio-economic status (Table 3 ). The frequency of stunting or underweight did not differ significantly according to socio-economic status in children with palpable goitre $(P>0.05)$. Similar to the whole population, among children without palpable goitre being stunted and underweight was significantly more common in those with low and very low socioeconomic status $(P<0.0001$ and 0.0126 respectively, $\mathrm{OR}=3.03$ ). The frequency of being underweight according to BMI was significantly different between children with different socio-economic status $(P<0.0001)$ (Table 4).

According to the results of logistic regression analysis, the most important parameters affecting the rate of palpable goitre were identified as BMI $Z$-score, WAZ, W/H and socio-economic status. Socio-economic status was the most important determinant of palpable goitre detection
( $B=0.517, P=0.040)$. Evaluation of parameters that determine socio-economic status revealed that the rate of goitre was higher in children with a father who had low educational level $\left(\chi^{2}=5.374, P=0.020\right)$ and in children whose father was occupied in a low-income job $\left(\chi^{2}=4.633, P=0.031\right)$.

\section{Discussion}

We did not assess IDD and goitre prevalence in this study but evaluated the rate of goitre detected by palpation in primary-school children of an urban area, revealing that $8 \%$ of these children had goitre. Most children who had palpable goitre were grade $1 \mathrm{~A}$, similar to the results obtained in areas of mild IDD in a previous study ${ }^{15}$. In agreement with the results of Brahmbhatt et al. ${ }^{16}$, we did not find gender differences in the frequency of goitre determined by palpation. Our study was performed in a city in the Aegean region in the west of Turkey. Children included in this study constituted a general sample of the child population of the city. The rates of stunting and underweight were $7.5 \%$ and $4.1 \%$, respectively. In a study carried out by the Ministry of Health, stunting and underweight rates were $6.6 \%$ and $0.8 \%$ respectively in children below 5 years of age living in the Aegean region in $2003^{17}$. There are no data on stunting and underweight prevalences among schoolchildren in Turkey. Global prevalences of stunting and underweight in 1990-2000 were reported to decline from 34 to $27 \%$ and from 27 to $22 \%$, respectively, by de Onis et al. ${ }^{9}$. The rates in our study are too low to compare with the values obtained in other developing countries.

Values of HAZ and WAZ were not significantly different between children with and without goitre. On the other hand, BMI $Z$-score and $\mathrm{W} / \mathrm{H}$ were significantly lower in children with goitre than in children without goitre. This led us to interpret that children with goitre were thinner and that their nutritional status was worse. Adults also show a very high prevalence of PEM, as evidenced by the prevalence of low BMI (a critical situation) in the population $^{18}$. Brahmbhatt et al. reported that thyroid volumes were higher in schoolchildren with malnutrition defined by low BMI. The mechanism of goitre in the setting of PEM is probably multifactorial. Iodine absorption decreases in children with $\mathrm{PEM}^{13}$. Moreover, iodine

Table 1 Anthropometric indices of the total population and children with and without palpable goitre

\begin{tabular}{lccc}
\hline & $\begin{array}{c}\text { Total }(n=1018), \\
\text { mean } \pm \text { SD }\end{array}$ & $\begin{array}{c}\text { Palpable goitre }(n=81), \\
\text { mean } \pm \text { SD }\end{array}$ & $\begin{array}{c}\text { No palpable goitre }(n=937), \\
\text { mean } \pm \text { SD }\end{array}$ \\
\hline HAZ & $-0.32 \pm 1.19$ & $-0.33 \pm 1.23$ & $-0.32 \pm 1.19$ \\
WAZ & $-0.19 \pm 1.17$ & $-0.40 \pm 1.08$ & $-0.17 \pm 1.17$ \\
BMI Z-score & $0.47 \pm 1.64$ & $0.17 \pm 1.15$ & $0.66 \pm 1.62$ \\
W/H (\%) & $98.56 \pm 14.90$ & $94.53 \pm 11.20$ & 0.549 \\
\hline
\end{tabular}

SD - standard deviation; HAZ - height-for-age Z-score; WAZ - weight-for-age Z-score; BMI - body mass index; W/H - weight-for-height.

* Student's $t$-test, significance defined as $P<0.05$. 
Table 2 Frequencies of stunting, underweight and wasting among children with and without palpable goitre

\begin{tabular}{lccc}
\hline & $\begin{array}{c}\text { Palpable } \\
\text { goitre } \\
(\%)\end{array}$ & $\begin{array}{c}\text { No palpable } \\
\text { goitre } \\
(\%)\end{array}$ & $P_{\text {-value* }}$ \\
\hline -score/category $(n)$ & 10.5 & 7.7 & 0.377 \\
HAZ $<-2(76)$ & 89.5 & 92.3 & 0.138 \\
HAZ $>-2(943)$ & 14.3 & 7.7 & 1.00 \\
WAZ $<-2(42)$ & 85.7 & 92.3 & \\
WAZ $>-2(975)$ & 7.6 & 7.9 & \\
BMl $<15 \mathrm{~kg} \mathrm{~m}^{-2}(91)$ & 92.4 & 92.1 & \\
BMI $>15 \mathrm{~kg} \mathrm{~m}^{-2}(927)$ & 9 &
\end{tabular}

HAZ - height-for-age Z-score; WAZ - weight-for-age Z-score; BMI - body mass index.

${ }^{*}$ Chi-square test, significance defined as $P<0.05$.

concentration in the thyroid gland decreases due to depressed iodide clearance and uptake ${ }^{19,20}$. Thus PEM may cause thyroid hyperplasia and further reduce the circulating levels of thyroid hormone. Moreover, PEM may contribute directly to goitrogenesis through the lack of substrate availability, particularly essential amino acids such as tyrosine ${ }^{21}$. Even mild PEM is reported to have detrimental effects on thyroid homeostasis in iodinedeficient areas $^{22}$.

Goitre detection rate was highest in children with low and especially very low socio-economic status. The most important factor in goitre detection by palpation was socio-economic status. Also, rates of stunting and underweight were significantly higher in children with very low socio-economic status compared with the other children. Similarly, in studies performed in other countries, the frequency of goitre and malnutrition was found to be

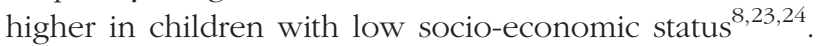
Rate of goitre detection was slightly higher in the stunted and underweight children with moderate socio-economic status. This may be a reflection of nutritional problems during the pre-school period due to the mother working and the child being cared for by a babysitter.

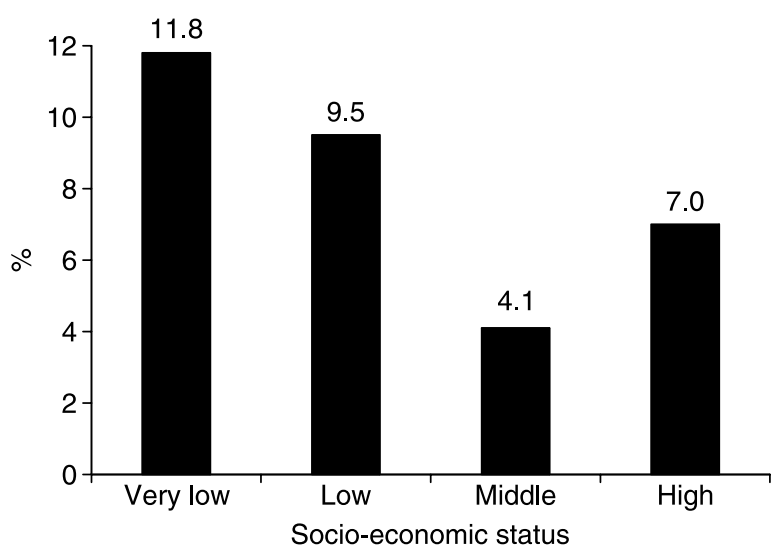

Fig. 1 Goitre rate in children according to socio-economic status. Frequency of palpable goitre was significantly higher in children with low socio-economic status $(P=0.001)$

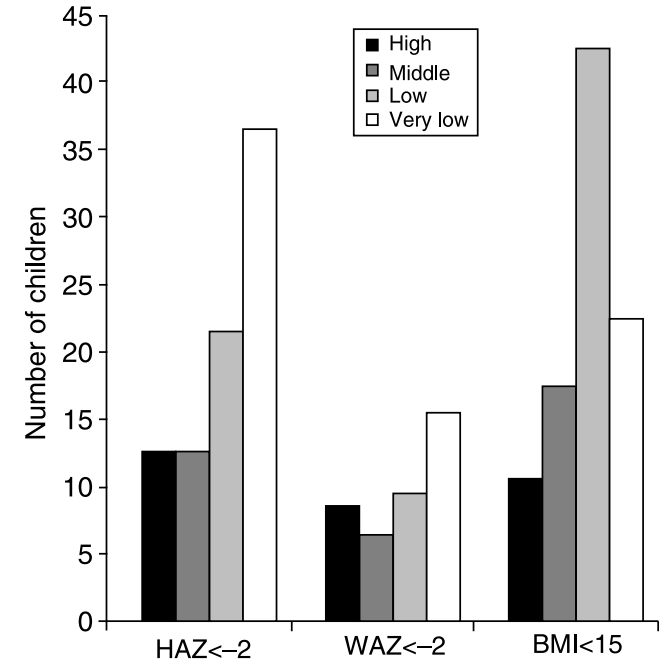

Nutritional status according to anthropometric indices

Fig. 2 Distribution of children who were stunted, underweight and wasted according to socio-economic status. Stunting (height-forage $Z$-score $(H A Z)<-2)$ was significantly higher in children with very low socio-economic status; thinness (wasting) (body mass index $(\mathrm{BMI})<15 \mathrm{~kg} \mathrm{~m}^{-2}$ ) was significantly higher in children with low socio-economic status; and underweight (weight-for-age Zscore (WAZ) <-2) was generally uncommon but significantly higher in children with very low socio-economic status

Although anthropometric indices differed between children with low and very low socio-economic status in the whole study population and in children without palpable goitre, in children with palpable goitre only WAZ differed according to low or very low socio-economic status. In a study from Malaysia, the coexistence of malnutrition and iodine deficiency was more common in areas of low socio-economic status; however, unlike in our study, the most commonly encountered nutritional deficiency was stunting and not underweight ${ }^{25}$. We found that the frequency of stunting and underweight among children without goitre was higher in those with low socio-economic status. On the other hand, the frequency of nutritional disorders among children with goitre did not change with socio-economic status. This may be explained by the inadequate nutrition of children with goitre independent of socio-economic status.

We found that low educational level of the father and father's occupation in a low-income job increased the rate of goitre; however, monthly income of the families was not questioned in this study. Goitre being more common in children whose fathers had low-income jobs can be interpreted that the role of economic factors is more important than the role of social factors in goitre frequency $^{26}$.

In summary, BMI and $\mathrm{W} / \mathrm{H}$ were lower in children who had goitre on palpation. However, the rate of palpable goitre in stunted and underweight children was not significantly higher than in children with normal nutritional status. Moreover, rates of palpable goitre and nutritional deficiencies were higher in children with low 
Table 3 Anthropometric indices among children with and without palpable goitre according to socio-economic status

\begin{tabular}{|c|c|c|c|c|c|}
\hline \multirow[b]{2}{*}{ Dependent variable } & \multirow{2}{*}{$\begin{array}{l}\text { Socio-economic } \\
\text { status }\end{array}$} & \multirow{2}{*}{$\begin{array}{c}\text { Palpable } \\
\text { goitre }^{\star} \text {, median }\end{array}$} & \multirow{2}{*}{$\begin{array}{c}\text { No palpable } \\
\text { goitre†, mean } \pm \text { SD }\end{array}$} & \multicolumn{2}{|c|}{$95 \% \mathrm{Cl}$} \\
\hline & & & & Lower & Upper \\
\hline \multirow[t]{4}{*}{ HAZ } & High & -0.14 & $0.004 \pm 1.16$ & -0.12 & 0.13 \\
\hline & Middle & 0.24 & $-0.14 \pm 1.04$ & -0.28 & -0.0007 \\
\hline & Low & -0.36 & $-0.54 \pm 1.10$ & -0.69 & -0.39 \\
\hline & Very low & -0.71 & $-0.80 \pm 1.27$ & -0.98 & -0.62 \\
\hline \multirow[t]{4}{*}{ WAZ‡ } & High & 0.06 & $0.26 \pm 1.25$ & 0.12 & 0.40 \\
\hline & Middle & -0.85 & $-0.10 \pm 1.11$ & -0.25 & 0.04 \\
\hline & Low & -0.72 & $-0.41 \pm 1.08$ & -0.56 & -0.26 \\
\hline & Very low & -0.81 & $-0.17 \pm 1.17$ & -0.24 & -0.09 \\
\hline \multirow[t]{4}{*}{ BMI Z-score } & High & 0.30 & $1.29 \pm 1.70$ & 1.10 & 1.48 \\
\hline & Middle & -0.30 & $0.82 \pm 1.70$ & 0.59 & 1.05 \\
\hline & Low & -0.55 & $0.21 \pm 1.46$ & 0.001 & 0.41 \\
\hline & Very low & -0.10 & $0.004 \pm 1.0$ & -0.17 & 0.10 \\
\hline \multirow[t]{4}{*}{ W/H (\%) } & High & 95.00 & $103.38 \pm 16.40$ & 101.57 & 105.18 \\
\hline & Middle & 92.00 & $99.38 \pm 16.06$ & 97.2 & 101.56 \\
\hline & Low & 88.00 & $96.36 \pm 13.97$ & 94.46 & 98.26 \\
\hline & Very low & 94.50 & $93.80 \pm 10.24$ & 92.35 & 92.25 \\
\hline
\end{tabular}

$\mathrm{SD}$ - standard deviation; $\mathrm{Cl}$ - confidence interval; HAZ - height-for-age Z-score; WAZ - weight-for-age Z-score; BMI - body mass index; W/H weight-for-height.

${ }^{*}$ Kruskal-Wallis test.

†One-way analysis of variance.

$\ddagger$ Mann-Whitney $U$-test, $P=0.001$.

Table 4 Frequency of palpable goitre in children who are stunted, underweight or wasted and in children with normal nutritional status according to socio-economic status

\begin{tabular}{|c|c|c|c|c|c|c|c|c|c|c|}
\hline \multirow[b]{3}{*}{ Z-score/category } & \multicolumn{4}{|c|}{ Palpable goitre (\%) } & \multicolumn{5}{|c|}{ No palpable goitre (\%) } & \multirow[b]{3}{*}{$P$-value } \\
\hline & \multicolumn{4}{|c|}{ Socio-economic status $(n)$} & \multirow[b]{2}{*}{$P$-value } & \multicolumn{4}{|c|}{ Socio-economic status $(n)$} & \\
\hline & High (24) & Middle (9) & Low (22) & Very low (26) & & High (321) & Middle (211) & Low (210) & Very low (195) & \\
\hline $\mathrm{HAZ}<-2$ & 4.2 & 11.1 & 9.1 & 15.4 & 0.616 & 3.4 & 2.8 & 9.0 & 16.4 & $<0.0001$ \\
\hline $\mathrm{HAZ}>-2$ & 95.8 & 88.9 & 90.9 & 84.6 & & 96.6 & 97.2 & 91.0 & 83.6 & \\
\hline WAZ $<-2$ & 4.2 & - & 11.5 & 7.4 & 0.609 & 2.5 & 2.8 & 3.3 & 7.2 & 0.0126 \\
\hline WAZ $>-2$ & 95.8 & 100.0 & 88.5 & 92.6 & & 97.5 & 97.2 & 96.7 & 92.8 & \\
\hline $\mathrm{BMI}<15 \mathrm{~kg} \mathrm{~m}^{-2}$ & 4.2 & - & 13.6 & 7.7 & 0.506 & 2.8 & 8.1 & 18.6 & 10.3 & $<0.0001$ \\
\hline $\mathrm{BMI}>15 \mathrm{~kg} \mathrm{~m}^{-2}$ & 95.8 & 100.0 & 86.4 & 92.3 & & 97.2 & 91.9 & 81.4 & 89.7 & \\
\hline
\end{tabular}

HAZ - height-for-age Z-score; WAZ - weight-for-age Z-score; BMI - body mass index.

and very low socio-economic status. In children who did not have goitre, all anthropometric indices were lower in those who had low and very low socio-economic status, but in children with palpable goitre only WAZ was lower. Among children without goitre, the frequency of being stunted and underweight was higher in those with low socio-economic status, but the frequency of nutritional disorders did not change according to socio-economic status among children with goitre. The high rate of goitre in children whose father had low educational level and whose father was occupied in a low-income job revealed the importance of economic factors in the development of goitre.

In conclusion, children detected to have goitre were thinner, but frequency of palpable goitre was not significantly increased in children with nutritional disorders. Both palpable goitre and nutritional disorders were encountered more commonly in the setting of low socio-economic status. Among children with palpable goitre, WAZ was lower in the ones with low socioeconomic status. However, the frequency of nutritional disorders in children with palpable goitre did not change according to socio-economic status. Economic status was the most important factor influencing the frequency of goitre.

\section{References}

1 Dreimane D, Varma SK. Common childhood thyroid disorders. Indian Journal of Pediatrics 1997; 64: 3-10.

2 Perez C, Scrimshaw NS, Munoz A. Technique of endemic goitre surveys. In: Endemic Goitre. Monograph Series No. 44. Geneva: World Health Organization, 1960; 369-83.

3 World Health Organization \& International Council for Control of Iodine Deficiency Disorders. Recommended normative values for thyroid volume in children aged 6-15 years. Bulletin of the World Health Organization 1997; 75: 95-7.

4 Delange F. What do we call a goiter? European Journal of Endocrinology 1999; 140: 486-8. 
5 Zimmermann MB, Hess SY, Adou P, Toresanni T, Wegmuller $\mathrm{R}$, Hurrell RF. Thyroid size and goiter prevalence after introduction of iodized salt: a 5-y prospective study in schoolchildren in Côte d'Ivoire. American Journal of Clinical Nutrition 2003; 77: 663-7.

6 Busnardo B, Nacamulli D, Frigato F, Vianello-Dri A, De Vido D, Mian C, et al. Normal values for thyroid ultrasonography, goiter prevalence and urinary iodine concentration in school children in Veneto Region, Italy. Journal of Endocrinological Investigation 2003; 26: 991-6.

7 Schuftan C, Ramalingaswami V, Levinson FC. Micronutrient deficiencies and protein energy malnutrition. Lancet 1998; 351: 1812 .

8 Joshi DC, Mishra VN, Bhatnagar M, Singh RB, Garg SK, Chopra H. Socioeconomic factors and prevalence of endemic goiter. Indian Journal of Public Health 1993; 37: $48-53$.

9 de Onis M, Blossner M, Borghi E, Morris R, Frongillo EA. Methodology for estimation regional and global trends of child nutrition. International Journal of Epidemiology 2004; 33: $1260-70$.

10 World Health Organization (WHO). Data analysis and interpretation. In: Measuring Change in Nutritional Status, 1st ed. Geneva: WHO, 1983; 19-28.

11 Dibley MJ, Staehling N, Nieburg P, Trowbridge FL. Interpretation of $Z$-score anthropometric indicators derived from international growth reference. American Journal of Clinical Nutrition 1987; 46: 749-62.

12 de Onis M, Blüssner M. World Health Organization Global Database on Child Growth and Malnutrition: methodology and applications. International Journal of Epidemiology 2003; 32: 518-26.

13 Brahmbhatt SR, Brahmbhatt RM, Boyages SC. Impact of protein energy malnutrition on thyroid size in an iodine deficient population of Gujarat (India): is it an aetiological factor for goiter? European Journal of Endocrinology 2001; 145: 11-17.

14 Hollingshead A. Two Factor Index of Social Position. New Haven, CT: Yale University Press, 1957.

15 Zimmerman M, Saad A, Hess S, Torresani T, Chaoki N. Thyroid ultrasound compared with World Health Organization 1960 and 1994 palpation criteria for determination of goiter prevalence in regions of mild and severe iodine deficiency. European Journal of Endocrinology 2000; 143 $727-31$.
16 Brahmbhatt S, Brahmbhatt RM, Boyages SC. Thyroid ultrasound is the best prevalence indicator for assessment of iodine deficiency disorders: a study in rural/tribal schoolchildren from Gujarat (Western India). European Journal of Endocrinology 2000; 143: 37-46.

17 Hacettepe University Institute of Population Studies. Turkey Demographic and Health Survey, 2003. Ankara: Hacettepe University Institute of Population Studies, Ministry of Health General Directorate of Mother and Child Health and Family Planning, State Planning Organization and European Union, 2003.

18 World Health Organization (WHO). Physical Status: The Use and Interpretation of Anthropometry. Report of a WHO Expert Committee. Technical Report Series No. 854. Geneva: WHO, 1995.

19 Ingenbleek Y, Beckers C. Evidence for intestinal malabsorbtion of iodine in protein-calorie malnutrition. American Journal of Clinical Nutrition 1973; 26: 1323-30.

20 Ingenbleek $\mathrm{Y}$, Beckers C. Thyroid iodine clearance and radioiodide uptake in protein-calorie malnutrition. American Journal of Clinical Nutrition 1978; 31: 408-15.

21 Gaitan JE, Mayoral LG, Gaitan E. Defective thyroidal iodine concentration in protein calorie malnutrition. Journal of Clinical Endocrinology and Metabolism 1983; 57: 327-33.

22 Centanni M, Miani G, Vermiglio F, Cannettieri G, Sanna AL, Moretti F, et al. Combined impairment of nutritional parameters and thyroid homeostasis in mildly iodinedeficient children. Thyroid 1998; 8: 155-9.

23 Stone T. Endemic goiter, nutrition and landholding in Bangladesh. International Journal of Epidemiology 1984; 13: 58-64

24 Knudsen N, Bülow I, Laurberg P, Ovesen L, Perrild H, Jorgensen $T$. Low socio-economic status and familial occurrence of goitre are associated with high prevalence of goitre. European Journal of Epidemiology 2003; 18: 175-81.

25 Wan Nazaimoon WM, Osman A, Wu LL, Khalid BA. Effects of iodine deficiency on insulin-like growth factor-I, insulin-like growth factor-binding protein-3 levels and height attainment in malnourished children. Clinical Endocrinology 1996; 45: $79-83$.

26 Hakeem R. Socio-economic differences in height and body mass index of children and adults living in urban areas of Karachi, Pakistan. European Journal of Clinical Nutrition 2001; 55: 400-6. 